\title{
Pelatihan Teknik Menanam Hidroponik Bagi Paguyuban Ibu-Ibu Santa Teresa Calcuta, Pasar Kliwon, Surakarta
}

\author{
Tri Wiharti ${ }^{1}$, Nur Rokhimah Hanik ${ }^{2}$, Anwari Adi Nugroho ${ }^{3^{*}}$ \\ ${ }^{123}$ Program Studi Pendidikan Biologi, Univeristas Veteran Bangun Nusantara Sukoharjo \\ *e-mail: bio_anwary@yahoo.com
}

\begin{abstract}
Abstrak
Pengamatan di rumah-rumah Desa Semanggi terutama RW 12 menunjukkan bahwa hampir setiap rumah terdapat sedikit lahan kebun dan sedikit tanaman khususnya sayuran. Wawancara dilakukan kepada beberapa warga RT 6, RW 12, Desa Semanggi menunjukkan bahwa warga khususnya Paguyuban Ibu-Ibu Santa Teresa Calcuta, Wilayah Santo Lucas, Semanggi, Pasar Kliwon, Surakarta kesulitan menanam beberapa tanaman sayur di area rumah mereka. Salah satu solusi yang ditawarkan kepada warga adalah cara penanaman sayuran melalui metode hidroponik. Penanaman sayuran dengan metode hidroponik memberi peluang untuk dapat menanam walaupun dengan lahan yang sempit. Tujuan dari pengabdian ini adalah untuk memberikan pelatihan cara penanaman sayuran melalui metode hidroponik. Metode yang digunakan terdiri dari beberapa tahap yaitu tahap pertama meliputi persiapan dan observasi kebutuhan, tahap kedua yaitu pemberian angket pretes, tahap ketiga yaitu penyampaian materi dan diskusi, tahap keempat yaitu praktek pembuatan hidroponik, tahap kelima yaitu praktek cara merawat tanaman hidroponik, dan tahap keenam yaitu pemberian angket postes. Hasil pelatihan pembuatan hidroponik diperoleh hasil semua peserta (11 peserta) memperoleh skor angket postes meningkat $25 \%$ dari skor pretes. Produk tanaman hidroponik hasil karya peserta dinilai dan memperoleh skor $\geq 70$ (skala 100) yang artinya sudah mencapai target minimal skor penilaian.
\end{abstract}

Kata kunci: Hidroponik, Pelatihan, Surakarta

\begin{abstract}
Observations in houses in Semanggi Village, especially RW 12 show that each house has only a small amount of garden land and a few vegetables specifically. Interviews were conducted with a number of residents of RT 6, RW 12, Semanggi Village. Circle of Friends, Ladies, Santa Teresa Calcuta, St. Lucas Region, Semanggi, Pasar Kliwon, Surakarta. One solution offered to residents is the method of planting vegetables through the hydroponic method. Growing vegetables using the hydroponic method provides an opportunity to be able to plant with limited land. The purpose of this service is to provide training in how to grow vegetables through the hydroponic method. The method used consists of several glasses, namely, first, prepared, and collected, glass, second, questionnaire assistance, and third, the delivery of material and discussion, and second, how to make hydroponics, and so on. namely giving questionnaire posture. The results of the hydroponic manufacturing training show that all participants (11 participants) obtained a questionnaire score increased by $25 \%$ from the pretest score. Hydroponic plant products of the participants' work obtained and obtained a score of $\geq 70$ (scale 100), which means they have reached the minimum score target.
\end{abstract}

Keywords: Hydroponics, Training, Surakarta

\section{PENDAHULUAN}

Masyarakat dahulu menanam sayuran dengan cara konvensional di lakukan di lahan kebun atau sawah yang luas. Penanaman dilakukan dengan mengolah lahan terlebih dahulu sebelum dilakukan penanaman. Pengolahan tanah dilakukan dengan cangkul dan alat pertanian lain yang sederhana. Setelah diolah tanah diberi pupuk dari jerami yang dibakar ditempat. Bila dibutuhkan pengairan, pengairan didapat dari aliran sungai yang dialirkan ke sawah atau dari tadah hujan (Depdikbud, 1989). Bercocok tanam dengan cara konvensional biasanya dilakukan di daerah pedesaan yang masih memiliki lahan kosong dan luas.. Namun di daerah perkotaan terutama di 
Pulau Jawa, halaman pekarangan pada umumnya sempit, dan tidak jarang sudah dilapisi dengan semen sehingga tidak dapat dimanfaatkan untuk bertanam sayuran.

Lahan pertanian semakin menyempit akibat peralihan lahan pertanian menjadi perumahanperumahan penduduk. Kebutuhan pendudukan akan tempat tinggal semakin lama semakin bertambah. Selain itu pembangunan fasilitas umum yang semakin banyak seperti pasar modern dan mall-mall semakin menggerus lahan pertanian. Oleh karena itu, penyempitan lahan pertanian akibat konversi lahan pertanian ke non pertanian semakin tak terhindarkan lagi. Luas lahan pertanian Indonesia dalam 135 tahun ke depan seluas 8,1 juta hektar akan habis. Berkurangnya lahan pertanian tentu mempengaruhi produksi sayuran yang saat ini masyarakat masih mengandalkan pertanian konvensional.

Pengamatan di rumah-rumah Desa Semanggi terutama RW 12 menunjukkan bahwa hampir setiap rumah terdapat sedikit lahan kebun dan sedikit tanaman khususnya sayuran. Wawancara dilakukan kepada beberapa warga RT 6, RW 12, Desa Semanggi menunjukkan bahwa warga khususnya Paguyuban Ibu-Ibu Santa Teresa Calcuta, Wilayah Santo Lucas, Semanggi, Pasar Kliwon, Surakarta kesulitan menanam beberapa tanaman sayur di area rumah mereka. Hal tersebut dikarenakan lahan untuk menanam sayur sedikit bahkan tidak ada. Sementara itu, minat warga cukup tinggi untuk dapat menanam sayur di area rumah. Permasalahan minimnya lahan kebun untuk menanam sayuran sementara minat untuk menanam sayur cukup tinggi, maka diperlukan solusi yaitu cara penanaman sayuran melalui metode hidroponik. Sebagian besar warga belum paham cara penanaman sayuran dengan metode hidroponik dan belum pernah ada pelatihan penanaman metode hidroponik. Raffar (1993) menjelaskan bahwa sistem hidroponik merupakan cara produksi tanaman yang sangat efektif. Jika dibandingkan dengan metode konvensional, maka metode hidroponik mempunyai keunggulan yaitu penggunaan lahan lebih efisien, tanaman berproduksi tanpa menggunakan tanah, tidak ada resiko untuk penanaman terus menerus sepanjang tahun, kuantitas dan kualitas produksi lebih tinggi dan lebih bersih, penggunaan pupuk dan air lebih efisien, periode tanam lebih pendek, dan pengendalian hama dan penyakit lebih mudah. (Del Rosario dan Santos, 1990; Chow ,1990).

Pelatihan penanaman sayuran dengan metode hidroponik kepada Paguyuban Ibu-Ibu Santa Teresa Calcuta, Wilayah Santo Lucas, dilaksanakan di RT 6, RW 12, Desa Semanggi, Pasar Kliwon, Surakarta dengan beberapa tahapan yaitu pretes untuk menguji kemampuan awal tentang cara penanaman metode hidroponik. Kemudian pemberian materi oleh Tim Abmas yang terdiri dari cara pembuatan hidroponik, penanaman sayuran dalam hidroponik, pemberian media dalam hidroponik dan cara perawatan tanaman dalam hidroponik. Setelah peserta menerima teori tentang hidroponik, pada pertemuan selanjutnya dilakukan workshop/praktek langsung cara membuat hidroponik hingga penanaman sayuran. Pertemuan selanjutnya dilakukan pendampingan cara merawat tanaman dalam hidroponik hingga pemberian pupuk. Pertemuan terakhir yaitu postes dan penilaian terhadap hasil hidroponik.

\section{METODE}

Solusi yang ditawarkan berupa pelatihan penanaman sayuran dengan metode hidroponik sistem sumbu (wick) kepada Paguyuban Ibu-lbu Santa Teresa Calcuta, Semanggi, Pasar Kliwon, Surakarta yang beralamat di RT 6, RW 12, Desa Semanggi, Kecamatan Pasar Kliwon, Surakarta. Pelatihan terdiri dari pretes, penyampaian materi hidroponik, praktek pembuatan hidroponik, praktek perawatan hidroponik, dan postes. Metode penerapan ipteks untuk pemecahan masalah (solusi) yang ditawarkan dalam kegiatan / pelatihan ini dapat digambarkan dalam langkah-langkah sebagai berikut. 


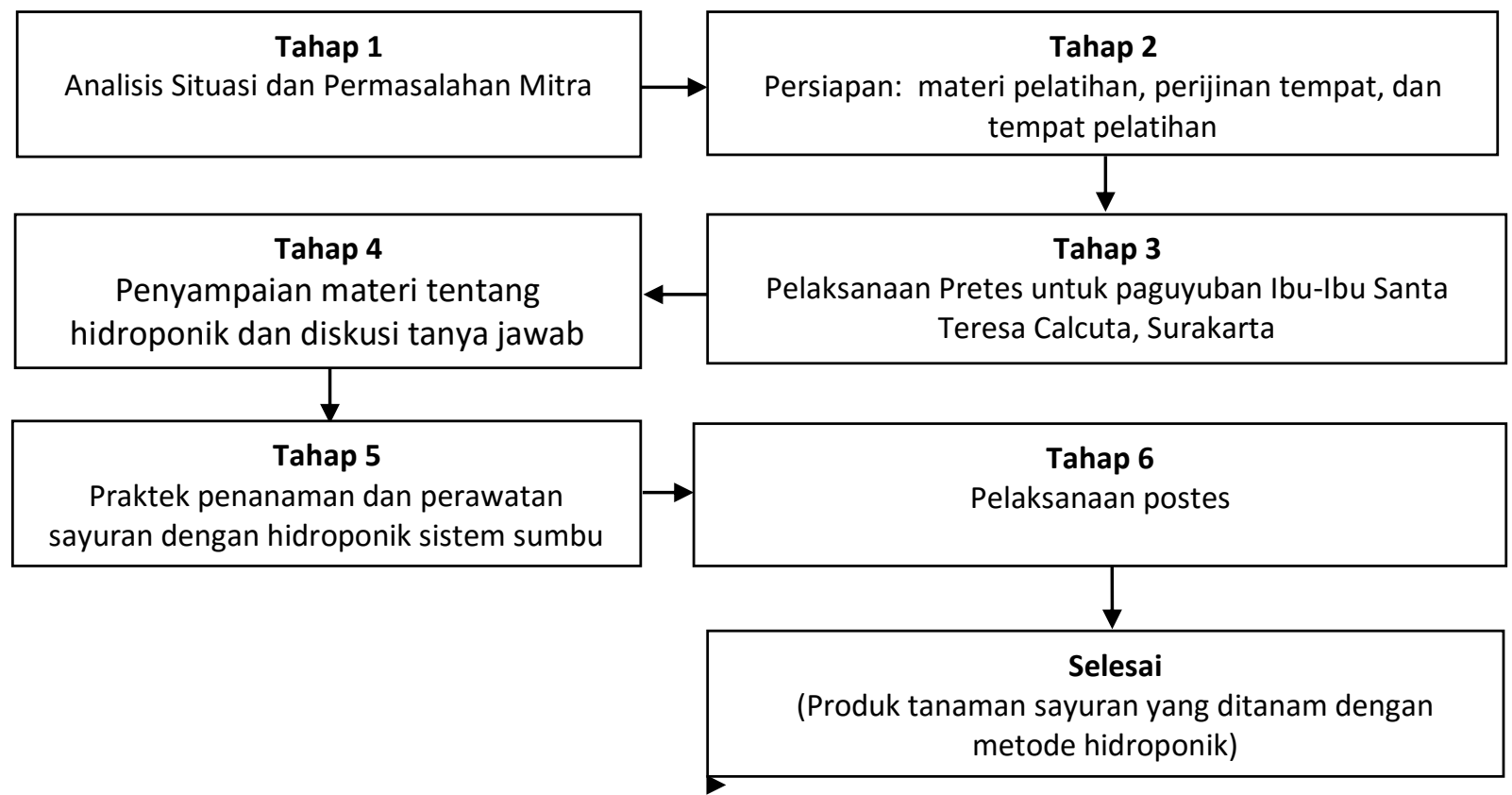

Gambar 1: Diagram alir langkah-langkah pemecahan masalah

Evaluasi diberikan untuk mengetahui kemampuan dasar dan peningkatan pengetahuan peserta terhadap materi dan praktek yang telah diberikan. Rancangan evaluasi dilakukan dengan mengerjakan soal yang berkaitan dengan materi dan praktek yang diberikan. Evaluasi diberikan dua kali berupa angket, sebelum program dimulai (angket pretes) dan setelah program selesai (angket postes). Nilai peserta program adalah skor total seluruh jawaban. Nilai keseluruhan adalah nilai rerata seluruh peserta program. Indikator keberhasilan program pengabdian adalah semua peserta yang mengikuti pelatihan memiliki skor rata-rata postes mengalami peningkatan dari skor pretes sebesar minimal $25 \%$.

Selain pretes dan postes untuk melengkapi ada tidaknya peningkatan pemahaman peserta sebelum memperoleh pelatihan penanaman sayuran dengan metode hidroponik dengan sesudah memperoleh pelatihan, juga dilakukan review / penilaian terhadap produk hidroponik yang dibuat para peserta. Target skor penilaian produk tanaman hidroponik minimal 70 (skala 100) setiap peserta.

\section{HASIL DAN PEMBAHASAN}

Pengabdian Pada Masyarakat dengan tema pelatihan penanaman tanaman sayuran dengan metode Hidroponik bagi paguyuban Ibu-lbu Santa Teresa Calcuta, Semanggi, Surakarta, telah dilaksanakan sampai pada tahap 6 yaitu tahap 1 kegiatan observasi ke desa semanggi, tahap ke 2 kegiatan persiapan materi, tahap 3 kegiatan pemberian pretes, tahap 4 kegiatan penyampaian materi, tahap 5 kegiatan bimbingan teknis penanaman dan perawatan, tahap 6 kegiatan postes. Pelaksanaan kegiatan PPM dimulai dari observasi ke Desa Semanggi pada tanggal 30 April 2016 untuk menentukan permasalahan melalui kegiatan wawancara kepada beberapa warga sekitar. Kegiatan observasi dilanjutkan pada tanggal 6 Mei 2016 dengan kegiatan menentukan tema PPM. Tema yang ditentukan yaitu tentang pelatihan penanaman tanaman sayuran dengan metode Hidroponik bagi paguyuban Ibu-Ibu Santa Teresa Calcuta, Semanggi, Surakarta. Kegiatan selanjutnya masih observasi ketiga pada tanggal 8 Mei 2016 untuk menentukan waktu pelaksanaan PPM. Tahap kedua yaitu kegiatan persiapan meliputi penyiapan materi pelatihan; yaitu; pengertian hidroponik, beberapa macam sistem dalam hidroponik, cara menanam dan perawatan dengan hidroponik sistem sumbu, 
kelabihan dan kekurangan metode hidroponik sistem sumbu dan lain lain. Persiapan lainnya adalah koordinasi dengan paguyuban Ibu-lbu Santa Teresa Calcuta, Semanggi, Surakarta untuk menyiapkan tempat, alat dan bahan untuk pelatihan.

Tahap ketiga kegiatan PPM pada tanggal 11 Juli 2016 adalah pemberian angket pretes tentang penanaman dengan metode hidroponik kepada 20 peserta Ibu-lbu Santa Teresa Calcuta, Semanggi, Surakarta. Pretes dilakukan selama 10 menit untuk mengetahui kemampuan awal peserta tentang metode hidroponik sebelum menerima pelatihan. Angket pretes berbentuk skala likert dengan 4 skala. Nilai/skor angket pretes digunakan sebagai patokan untuk menentukan keberhasilan pelatihan penanaman sayuran dengan metode hidroponik.

Tahap keempat kegiatan PPM pada tanggal 11 Juli 2016 (setelah pretes) yaitu kegiatan penyampaian materi hidroponik Sebelum penyampaian materi didahului oleh pembukaan dari ketua Paguyuban Ibu-Ibu Santa Teresa Calcuta, Semanggi, Surakarta yaitu Ibu Nawarti. Jumlah peserta yang hadir dalam tahap ketiga ini yaitu 20 peserta dari Paguyuban Ibu-Ibu Santa Teresa Calcuta, Semanggi, Surakarta. Penyampaian materi I oleh Dra. Tri Wiharti, M.Si. berlangsung selama 45 menit. Peserta diberi handout materi I untuk membantu peserta dalam memahami materi. Inti materi BAB I yang disampaikan antara lain 1) Latar belakang masalah mitra di desa Semanggi, Pasar Kliwon, Surakarta; 2) Solusi untuk mitra yaitu penanaman dengan metode hidroponik; 3) Pengertian, Kelebihan dan kekurangan hidroponik. Selanjutnya penyampaian materi II oleh Dra. Nur Rokhimah Hanik M.P. berlangsung selama 45 menit. Peserta diberi handout materi II untuk membantu peserta dalam memahami materi. Inti materi II yang disampaikan antara lain : teknik/sistem dalam metode hidroponik, media tanam hidroponik, nutrisi hidroponik. Kemudian penyampaian materi III oleh Anwari Adi Nugroho, S.Pd., M.Pd., berlangsung selama 45 menit. Peserta diberi handout materi III untuk membantuk peserta dalam memahami materi. Inti materi III yang disampaikan antara lain, 1) metode hidroponik sistem sumbu, 2) alat dan bahan metode hidroponik sistem sumbu, 3) cara penanaman metode hidroponik sistem sumbu 4) cara perawatan metode hidroponik sistem sumbu.
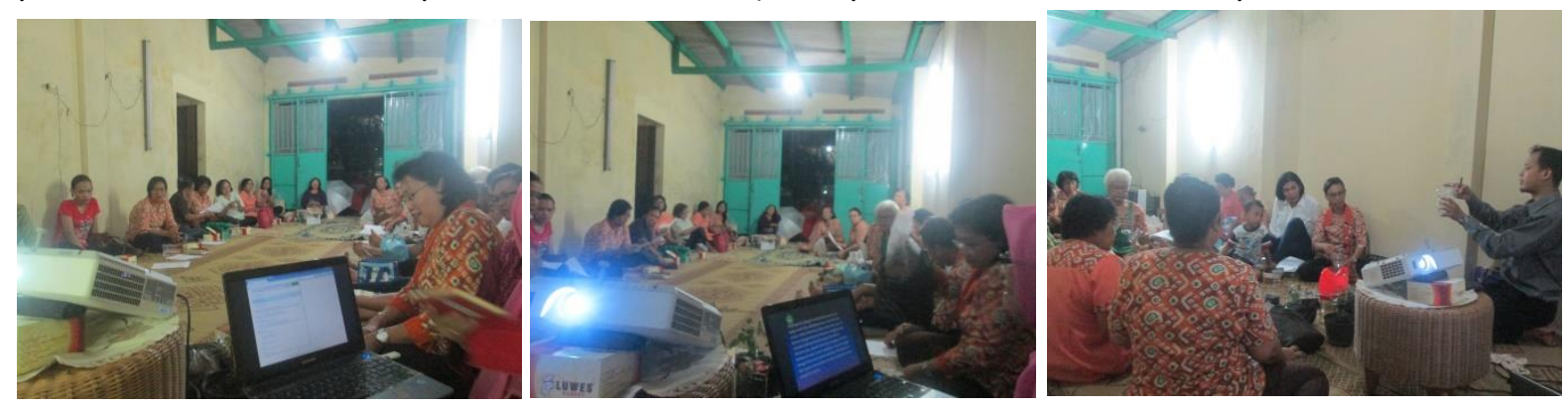

Gambar 2. Penyampaian Materi Oleh Tim PPM

Kegiatan berlangsung kondusif dan minat peserta cukup tinggi. Peserta banyak berdiskusi dan tanya jawab selama penyampaian materi. Hal tersebut dikarenakan masih banyak dijumpai peserta yang masih belum memahami metode hidroponik. Pada Pertemuan ini, para peserta juga dikenalkan dengan alat dan bahan yang akan digunakan dalam praktek dan tempat pembeliannya. Peserta juga diberi beberapa contoh tanaman yang ditanam secara hidroponik sistem sumbu. Tahap kelima dilaksanakan pada tanggal 19 Juli dan 28 Juli 2016 yaitu pembuatan/penanaman tanaman sayuran dengan metode hidroponik sistem sumbu serta cara perawatannya. Peserta dibimbing untuk membuat hidroponik dengan alat dan bahan yang sudah tersedia. 

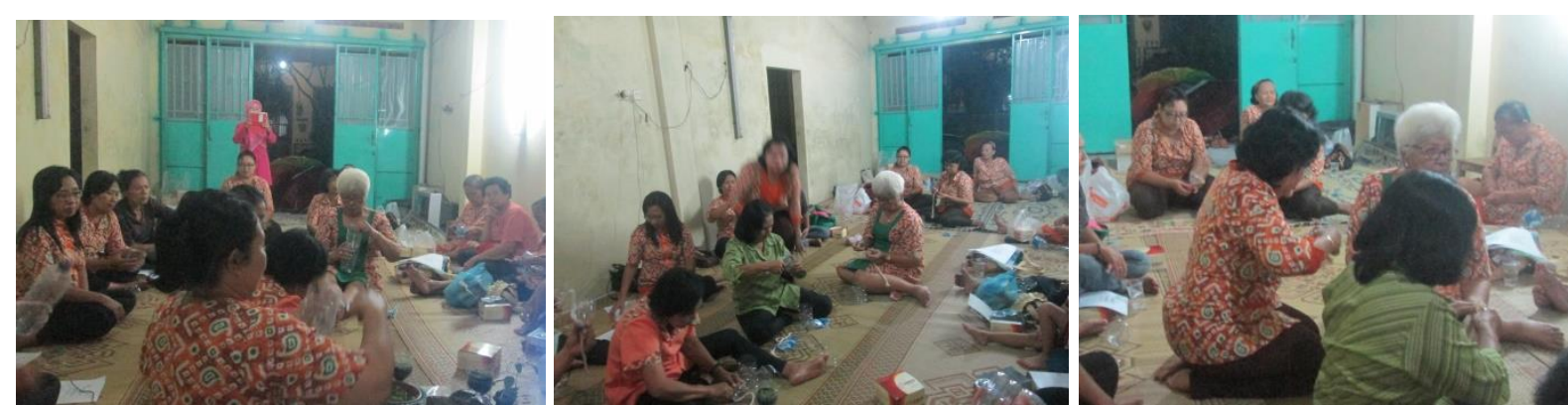

Gambar 3. Praktek Pembuatan Hidroponik

Setelah peserta menyiapkan alat dan bahan maka dilaksanakan pembuatan hidroponik sistem sumbu. Cara pembuatan hidroponik sistem sumbu yaitu 1) memotong botol bekas menjadi 2 bagian dengan ukuran $3 / 4$ bagian bawah dan $1 / 4$ bagian atas, 2 ) melubangi tutup botol dengan paku, 3) memotong sumbu kompor kira-kira $10 \mathrm{~cm}$ kemudian memasukkan ke dalam lubang tutp botol, 4) melubangi secukupnya dengan paku/gunting bagian dekat tutup botol sebagai jalan akar tanaman dapat menembus ke dalam, 5) memasang bagian potongan atas botol tadi dalam posisi terbalik dengan bagian potongan bawah botol, 6) menaruh media sekam dan kompos dengan perbandingan 1:1 ke dalam bagian potongan atas botol, 7) menanam bibit tanaman, 8) menyiram tanaman dengan air biasa. Media tanamn dapat diganti dengan rockwool tetapi harus diberi pupuk khusus hidroponik yaitu pupuk $A B$ mix.
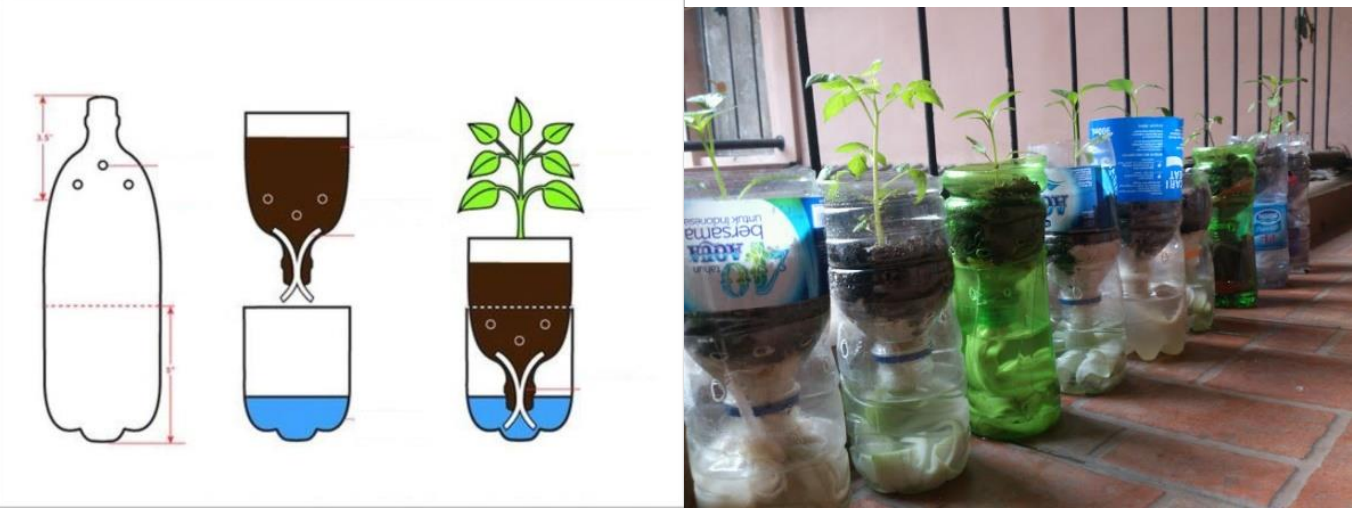

Gambar 4. Cara Membuat Hidroponik Sistem Sumbu

Setelah peserta membuat hidroponik, kemudian dijelaskan cara perawatan tanaman. Perawatan tanaman dilakukan seminggu sekali dengan mengecek kondisi media dan air. Apabila media kurang air maka ditambah dengan air/pupuk secukupnya. Selain itu, hidroponik diletakkan di tempat yang terkena sinar matahari langsung, tetapi terlindung dari hujan. Apabila sudah dalam masa panen, maka tanaman sayuran dicabut, kemudian diganti dengan bibit baru. Tahap keenam pada tanggal 28 Juli 2016 adalah pemberian angket postes kepada 11 peserta paguyuban ibu-ibu Santa Teresa Calcuta, Semanggi, Pasar Kliwon, Surakarta. Postes seharusnya dilakukan terhadap 20 peserta, namun 8 peserta tidak mengikuti pelatihan perawatan secara penuh dan tidak mengikuti postes. Postes dilakukan selama 20 menit untuk mengetahui kemampuan akhir peserta setelah menerima pelatihan. Nilai/skor angket postes digunakan sebagai patokan untuk menentukan keberhasilan pelatihan.

Evaluasi terhadap tingkat pemahaman peserta tentang penanaman sayuran dengan metode hidroponik sistem sumbu dilakukan dua kali, yaitu angket pretes dan angket postes. Nilai hasil angket 
pretes dan angket postes kemudian dibandingkan untuk mengetahui peningkatan pemahaman peserta sebelum memperoleh pelatihan dengan sesudah memperoleh pelatihan.

Tabel 1. Hasil Penilaian Angket Pretes dan Postes

\begin{tabular}{ccccc}
\hline Peserta & Skor Pretes & Skor Postes & Peningkatan (\%) & Target Peningkatan (\%) \\
\hline 1 & 1,6 & 3,6 & 0,56 & \\
2 & 1,5 & 3,6 & 0,58 & \\
3 & 1,6 & 3,8 & 0,58 & Minimal 25\% \\
4 & 1,4 & 3,7 & 0,62 & \\
5 & 1,2 & 3,7 & 0,68 & \\
6 & 1,3 & 3,9 & 0,67 & \\
7 & 1,2 & 3,6 & 0,67 & \\
8 & 1,8 & 3,8 & 0,53 & \\
9 & 1,6 & 3,7 & 0,57 & \\
10 & 1,4 & 3,7 & 0,62 & \\
11 & 1,2 & 3,7 & 0,68 & \\
\hline Jumlah & 27,9 & 40,8 & \\
\hline Rata-rata & 2,66 & 3,71 &
\end{tabular}

Berdasarkan Tabel 1 dapat diketahui rata-rata skor angket pretes sebesar 2,66 dari skala 4. Hal tersebut menunjukkan bahwa pemahaman tentang penanaman sayuran dengan metode hidroponik masih rendah dan perlu adanya pelatihan penanaman sayuran dengan metode hidroponik. Setelah menerima pelatihan (penyampaian materi, bimbingan teknis pembuatan hidroponik, bimbingan teknis perawatan tanaman hidoponik), peserta yaitu paguyuban ibu-ibu Santa Teresa Calcuta menghasilkan produk berupa tanaman sayuran yang ditanam dengan metode hidroponik sistem sumbu. Pada akhir pertemuan, dilaksanakan postes untuk mengukur kemampuan tentang penanaman sayuran dengan metode hidroponik. Hasil rata-rata postes yaitu sebesar 3,71 dari skala 4, sedangkan peningkatan skor setiap peserta diperoleh hasil lebih dari $25 \%$ yang berarti peningkatan dari pretes ke postes sudah memenuhi target.

Tabel 2. Hasil Penilaian Produk Hidroponik

\begin{tabular}{ccc}
\hline Peserta & Skor review (skala 100) & Target Skor \\
\hline 1 & 92 & \\
2 & 80 & \\
3 & 72 & Minimal 70 \\
4 & 88 & (skala 100) \\
5 & 72 & \\
6 & 88 & \\
7 & 80 & \\
8 & 76 & \\
9 & 72 & \\
10 & 80 & \\
11 & 80 & \\
\hline Jumlah & 880 & \\
\hline Rata-rata & 80 & \\
\hline
\end{tabular}

Produk pelatihan pembuatan hidroponik yaitu tanaman hidroponik juga dinilai. Berdasarkan Tabel 2, perolehan skor review produk hidroponik hasil pelatihan setiap peserta yaitu lebih dari 70 yang artinya sudah memenuhi target minimal skor 70 (skala 100).

Hasil pelatihan pembuatan hidroponik sistem sumbu bagi Paguyuban Ibu-Ibu Santa Teresa Calcuta, Wilayah Santo Lucas, Semanggi, Pasar Kliwon, Surakarta menunjukkan hasil rata-rata angket pretes sebesar 2,66 (skala 4) dengan kategori rendah. Skor angket pretes yang rendah tentang hidroponik disebabkan oleh peserta yang belum memahami tentang hidroponik mulai dari cara pembuatan hingga perawatannya. Ibu-lbu Santa Teresa Calcuta membutuhkan pelatihan pembuatan hidroponik guna mengatasi masalah minimnya lahan untuk menanam sayuran. Minat dan antusias 
peserta pelatihan cukup tinggi dibuktikan dengan semua anggota yang berjumlah 20 dari Paguyuban Ibu-Ibu Santa Teresa Calcuta datang pada pelatihan hari pertama (penyampaian materi). Semua peserta menerima handout materi pelatihan pada saat penyampaian materi tentang hidroponik sebagai bekal untuk praktek pembuatan hidroponik. Pada pertemuan selanjutnya, peserta membuat hidroponik sistem sumbu dengan alat dan bahan yang sudah disediakan.

Pada praktek pembuatan hidroponik, hanya 11 peserta yang datang. Beberapa bibit tanaman yang digunakan untuk hidroponik yaitu cabai, sawi, kemanggi, bayam, dan kangkung. Setiap peserta membuat 1 hidroponik dan ditanami 1 jenis tanaman sayuran. Pada awal pembuatan hidroponik ditemui beberapa peserta yang kesulitan dalam memotong botol, melubangi botol, dan memasang hasil potongan botol, sehingga diperlukan proses pembuatan yang berulang untuk mendapatkan hasil yang maksimal. Selama proses pembuatan hidroponik banyak juga peserta yang bertanya pada tim dan berdiskusi dengan peserta lain tentang proses pembuatannya. Terdapat juga peserta yang membuat lebih dari satu hidroponik dikarenakan waktu yang masih ada dan tersedianya alat-bahan yang banyak. Hasil dari pertemuan ini adalah semua peserta dapat membuat hidroponik sayuran. Selanjutnya, pelatihan perawatan tanaman hidroponik meliputi penyiraman, pemupukan dan pemberian herbisida. Pelatihan perawatan tanaman hidroponik dilakukan oleh setiap peserta pada hidroponik yang telah dibuat. Pada pelatihan perawatan dijumpai beberapa tanaman yang belum tumbuh secara maksimal, yang dikarenakan kondisi bibit sayuran dan lingkungan yang rawan hama tanaman.

Pada akhir pelatihan ini, produk hidroponik direview dan dinilai kelayakannya. Perolehan rata-rata skor review produk hidroponik hasil pelatihan adalah 80 (skala 100), sedangkan skor review produk hidroponik setiap peserta yaitu lebih dari 70 yang artinya sudah memenuhi target minimal skor 70 (skala 100). Peserta juga mengisi angket postes untuk mengetahui tingkat pemahaman pembuatan hidroponik setelah memperoleh pelatihan. Hasil pretes dan postes dibandingkan untuk mengetahui peningkatan pemahaman tentang hidroponik setelah menerima pelatihan. Hasil postes kemudian dihitung dengan hasil pretes untuk mengetahui peningkatan. Hasil peningkatan skor yaitu diatas $25 \%$ yang artinya sudah memenuhi target. Kegiatan pelatihan pembuatan hidroponik untuk paguyuban ibu-ibu Santa teresa Calcuta, Semanggi, Pasar Kliwon, Surakarta berlangsung dengan lancar sesuai dengan rencana dan target. Keterampilan dan pemahaman peserta tentang pembuatan hidroponik sudah maksimal setelah pelatihan. Produk hidroponik yang telah dibuat oleh peserta akan tetap dirawat sampai menghasilkan sayuran, sehingga dapat meningkatkan produktivitas ibu-ibu peserta pelatihan yang sebagian besar ibu rumah tangga.

\section{SIMPULAN}

Pelatihan penanaman sayuran dengan metode hidroponik bagi paguyuban ibu-ibu Santa Teresa, Calcuta, Semanggi, Pasar Kliwon, Surakarta dapat disimpulkan bahwa:pelatihan penanaman sayuran dengan metode hidroponik diperoleh hasil semua peserta (11 peserta) memperoleh skor postes yang meningkat $25 \%$ dari skor pretes. Produk Hidroponik hasil karya peserta dinilai dan memperoleh skor $\geq 70$ (skala 100) yang artinya sudah mencapai target minimal skor penilaian produk.

Pelatihan penanaman sayuran dengan metode hidroponik bagi paguyuban ibu-ibu Santa Teresa, Calcuta, Semanggi, Pasar Kliwon, Surakarta dapat dilanjutkan lagi dengan pelatihan pembuatan hidroponik sistem yang lain seperti sistem pipa yang memiliki produktivitas hasil sayuran lebih tinggi dibandingkan dengan sistem sumbu.

\section{UCAPAN TERIMA KASIH}

Penulis mengucapkan terima kasih kepada pihak-pihak yang telah membantu pelaksanaan kegiatan pengabdian kepada masyarakat ini antara lain LPPM Univet Bantara Sukoharjo yang 
membantu dalam pendanaan, mitra (paguyupan ibu-ibu Santa Teresa, Calcuta, Pasar Kliwon, Surakarta) yang teh mendukung penuh kegiatan ini sehingga dapat berjalan dengan lancar.

\section{DAFTAR REFERENSI}

Badan Penelitian dan Pengembangan Pertanian Departemen Pertanian dan Direktorat Jenderal Pendidikan Tinggi Depdikbud (1989). Prosiding Lokakarya Penelitian Komoditas dan Study Khusus.

Chow, V. (1990). The Commercial approach in hydroponics. International Seminar on Hydroponic Culture of High Value Crops in the Tropics in Malaysia, November 25-27, 1990.

Del Rosario, A. Dafrosa, and P.J.A. Santos. (1990). Hydroponic culture of crops in the Philippines: Problems and prospect. International Seminar on Hydroponic Culture of High Value Crops in the Tropics in Malaysia, November 25-27, 1990.

Raffar, K.A. (1990). Hydroponics in tropica. International Seminar on Hydroponic Culture of High Value Crops in the Tropics in Malaysia, November 25-27, 1990. 